\title{
ARTIGOS
}

\section{POR UMA EDUCAÇÃO NÃO TRANSFÓBICA: RECONHECIMENTO E PRODUÇÃO DE VERDADES TRANS NA EDUCAÇÃO}

Marco Antonio TORRES

Universidade Federal de Ouro Preto - UFOP

Mariana, Minas Gerais - Brasil torresgerais@gmail.com https://orcid.org/0000-0002-7120-3820

Rubens Gonzaga MODESTO zUniversidade Federal de Ouro Preto - UFOP

Mariana, Minas Gerais - Brasil rubensmodesto2006@yahoo.com.br https://orcid.org/0000-0002-3587-6681

Thaynara Martins da Costa de MENEZES Universidade Federal de Ouro Preto - UFOP

Mariana, Minas Gerais - Brasil thaynaramc.menezes@gmail.com https://orcid.org/0000-0002-7480-2407

Resumo: Os relatos de pessoas transsobre educação têm exposto insuficiências da formação docente que precisam ser problematizadas. No presente artigo analisamos como o discurso transfóbico impede ou dificulta extremamente a produção de inteligibilidade de formas de existência para além da cisheteronormatividade. Nossos diálogos teóricos foram realizados a partir de Judith Butler e Michel Foucault, bem como autoras trans que analisam o contexto escolar. Estas, com suas experiências, mobilizam e desenham transformações de regimes de verdade bem como podem contribuir no combate do discurso transfóbico. Por fim, destacamos um desafio posto à formação docente: aprender a deixar em aberto nossas definições sobre as sexualidades, abrindo-se às autodefinições de pessoas trans. Desse modo, nos propomos ao exercício de aprender comautoras trans sobre uma educação não transfóbica, de aprender comosuas experiências podem produzir posições críticas no contexto da formação docente.

Palavras-chave: Formação docente. pessoas trans. transfobia. reconhecimento. 


\title{
FOR A NON-TRANSFÓBIC EDUCATION: RECOGNITION AND PRODUCTION OF TRANS TRUTHS IN EDUCATION
}

\begin{abstract}
The reports of transgender people on education have exposed shortcomings in teacher education that need to be addressed. In the present article we analyze how the transphobic discourse prevents or makes it extremely difficult to produce intelligibility of forms of existence beyond cisheteronormativity. Our theoretical dialogues were carried out from Judith Butler and Michel Foucault, as well as trans authors who analyze the school context. These, with their experiences, mobilize and design transformations of truth regimes as well as can contribute to the fight against transphobic discourse. Finally, we highlight a challenge posed to teacher training: learning to leave open our definitions of sexualities, opening up to the self-definitions of trans people. In this way, we propose the exercise of learning from trans authors about non-transphobic education, of learning how their experiences can produce critical positions in the context of teacher education
\end{abstract}

Keywords: Teacher training. trans people. transphobia. recognition.

\section{PARA LA EDUCACIÓN NO TRANSFÓBICA: RECONOCIMIENTO Y PRODUCCIÓN DE VERDADES TRANS EN LA EDUCACIÓN}

Resumen: Los informes de personas transgénero sobre educación han expuesto deficiencias en la formación docente que deben abordarse. En este artículo, analizamos cómo el discurso transfóbico previene o hace extremadamente difícil producir inteligibilidad de formas de existencia más allá de la cisheteronormatividad. Nuestros diálogos teóricos fueron realizados por Judith Butler y Michel Foucault, así como por autores trans que analizan el contexto escolar. Estos, con sus experiencias, movilizan y diseñan transformaciones de los regímenes de verdad y pueden contribuir a la lucha contra el discurso transfóbico. Finalmente, destacamos un desafío que se plantea a la formación docente: aprender a dejar abiertas nuestras definiciones de sexualidades, abriéndose a las autodefiniciones de las personas trans. De esta manera, proponemos el ejercicio de aprender de los autores trans sobre la educación no transfóbica, de aprender cómo sus experiencias pueden producir posiciones críticas en el contexto de la formación docente.

Palabras-clave: Formación docente. personas trans. Transfobia. reconocimiento. 


\section{autêntica}

DOI https://doi.org/10.31639/rbpfp.v12i24.339

\section{Introdução}

O presente artigo resulta de um projeto de pesquisa que investiga processos de reconhecimento das sexualidades na Educação. Ao longo de nossas pesquisas percebemos a necessidade de analisar as implicações da transfobia na formação docente, considerando o sofrimento que experimentam travestis, transexuais, transgêneros, entre outros sujeitos, dos domínios da transgerneridade, em suas trajetórias escolares. Estes passam por processos de violência e/ou subalternizações, que não raro, os levam à evasão escolar, geralmente, por não contarem com apoio de educadores/as que poderiam contribuir no enfrentamento de tal situação. Isto fere princípios elementares de uma educação que se pretende democrática e minimamente justa com aqueles/as que por ela passam.

Consideramos que uma possibilidade de enfrentamento dessa situação seja a problematização da cisheteronormatividade e do discurso transfóbico ainda muito presente na formação docente. Para isso, uma das principais estratégias que avaliamos é a elaboração de análises que se disponham a dialogar com a produção de conhecimentos que travestis, transexuais, entre outros sujeitos marcados pelas sexualidades, têm elaborado. Esses conhecimentos têm sido elaborados na academia, nos movimentos sociais, bem como nas escolas (da vida), conforme definiu Adriana Sales (2019) ao pesquisar travestis brasileiras e o contexto escolar. O termo cis, em articulação com a noção de heteronormatividade, se relaciona com esse contexto de uma militância transfeminista contemporânea, como analisa Amara Moira (2017).

A transfobia, como produção do discurso transfóbico, é extremamente danosa nos contextos educacionais(SALES, 2019; FRANCO, 2018; SANTOS, 2017; XXXX, 2012), principalmente ao se considerar a função regulatória que a educação escolar tem nas dinâmicas sociais contemporâneas. A grande maioria de estudantes trans tem pouquíssimas possibilidades de acessar redes de apoio, muitas vezes suportando sofrimentos e humilhações silenciosamente e, não raro algo, culpabilizando-se por isto.

Pesquisadoras trans, como Marina Reidel (2013), relatam ter encontrado mais apoio no aluando do que entre seus pares quando passou a performar a travestilidade. Outras pesquisadoras trans relatam situações parecidas, indicando que somente por força de normativas tinham asseguradas algumas formas de reconhecimento como nome o uso do nome social, o uso de banheiros etc. (SALES, 2019; ANDRADE, 2015). Também isto aparece em outras pesquisas que investigaram docentes trans (FRANCO, 2018, SANTOS, 2017; TORRES, 2012). Isto pode estar relacionado a uma discussão ainda insuficiente, da temáticatrans, na formação docente. Uma pesquisa que examinou 1.076 grades curriculares, de cursos de Pedagogia e dos Programas Especiais de Formação Pedagógico de docentes no Brasil, constatou uma total ausência de qualquer menção a travestilidade e transexualidade (GROSSI; OLIVEIRA; SILVA, 2017).

No presente artigo trazemos inicialmente questões específicas para uma aproximação ética da temática das sexualidades, principalmente explicando como temos assumidos certas posições metodológicas e políticas no campo acadêmico. Compreendemos os corpos que se inserem nos domínios trans como performatividades de gênero, a partir de Judith Butler (2003). Essa autora propõe uma elaboração que busca erradicar de uma semântica política e teórico-metodológica quaisquer substância e essência do gênero. Este, nessa elaboração, se constituipor uma reiteração de atos corpóreos que nunca logram perfeição na repetição das normas de gênero, ou seja, do privilégio do masculino, do dimorfismo sexual e da heterossexualidade compulsória.Também dialogamos com as noções de reconhecimento (BUTLER, 2015) e de regime de verdade (FOUCAULT,2018), bem como outras noções teórico-metodológicas que consideramos importantes pertinentes para nossa argumentação. Em seguida, nomeamosem nosso levantamento bibliográfico as produções que 


\section{autêntica}

DOI https://doi.org/10.31639/rbpfp.v12i24.339

se relacionam especificamente com as sexualidades e a formação docente, bem como a produção discursiva de relatos de travestis e/ou transexuais que dizem dos contextos educacionais.

Posteriormente trazemos a análise de uma entrevista narrativa com uma professora que se autodefine como mulher transexual para problematizarmos o discurso transfóbico na escola, bem como a relação desse contexto com a formação docente. Por fim, consideramos que existe a necessidade de maiores debates sobre as questões trans na formação de professores/as. Isto poder indicar caminhos para enfrentarmos o discurso transfóbico que produz e organiza os corpos na escola, produzindo formas de violência no cotidiano escolar historicamente desconsideradas por educadores/as.

\section{Aproximações metodológicas do discurso transfóbico: diálogos teóricos sobre reconhecimento e regimes de verdade}

Para analisar o discurso transfóbico operamos com a noção de análise do discurso de Michel Foucault, principalmente no contexto da década de 1980, quando a noção de governo é proposta em relação a de poder. Nesse contexto, a situação em que emerge o enunciado e o estatuto do sujeito falante ganham importância (FOUCAULT, 2018), numa performatividade própria da pragmática do discurso.Tal discurso, definido como transfóbico no contexto das lutas sociais de pessoas trans, reduz o gradiente democrático-participativo no contexto escolar, bem como em outros contextos sociais.

Neil Franco define que "o fenômeno da transfobia pode ser definido como um processo de recusa histórica, social e cultural pela forma como travestis, transexuais e transgêneros constroem seu gênero e vivem suas sexualidades" (2018, p. 476). Todavia, Viviane Vergueiro (2015) analisa como problemática a individualização da noção de transfobia. Ponderamos que isto não deixa de possuir certa razão, mas quando entendemos a transfobia na perspectiva do discurso a deslocamos da individualização. A pesquisadora e ativista Adriana Sales ao pesquisar a relação entre travestis e os processos educacionais, ou seja, escolas (da vida), define a transfobia do seguinte modo.

Ao adentrar nestes locais, quando conseguem este feito, nem sempre (quase nunca) tem suas demandas respeitadas e inclusas nestas relações e, de acordo com as experimentações de nossas participantes, resultam processos violentos de exclusão, crimes de ódio e violências físicas e mentais: o que estamos definindo aqui como transfobia. (SALES, 2019, p. 211).

Desde modo, analisamos que transfobia é uma noção que transitou da dimensão êmica para se tornar categoria das políticas públicas, elaborações acadêmicas e articulações políticas das lutas sociais. Isto se deu a partir de uma gramática do movimento social de travestis e transexuais, donde deriva grande legitimidade para seu uso em nossas argumentações. Endentemos que a transfobia funciona como um dispositivo, no sentido foucaultiano, que opera numa dinâmica, a partir de certo regime de verdade (BUTLER, 2015; FOUCAULT, 2018). Este, não estaria localizado dentro ou fora do indivíduo, mas numa discursividade em que se produzem e são produzidas nossas vidas, aqui incluídos os tristes desfechos de tentativas e efetivação de assassinatos e suicídios de LGBTQIA+ (lésbicas, gays, bissexuais, travestis, transexuais, queer, interessexuais, assexuais, entre outras identidades ou expressões das sexualidades). Essa sigla e suas variações dizem dos processos de reconhecimento dentro e fora dos movimentos sociais, indicando processos marcados pela reflexividade dos sujeitos.

Partindo dessas considerações, nossas análises têm problematizado elementos a serem pensados na formação docente a partir de relatos trans. Consideramos que o termo "trans" pode ser bastante complexo (MOIRA, 


\section{autêntica}

DOI https://doi.org/10.31639/rbpfp.v12i24.339

2017), contudo, aqui fazemos uso dele diante da precariedade de nossa linguagem acadêmico-científica em dizer das identidades ou expressões de gênero que se localizam além do binarismo de gênero, ou no embaralhamento de seus limites.

Além dos desafios das linguagens e não fixidez das noções no campo das sexualidades, temos questões metodológicas bastante específicas, estas relacionadas a posições teórico-políticas que assumem pesquisadores/as nessa área. Aqui destacamos duas, uma que diz do modo como nos apropriamos da produção de saberes e fazeres trans e outra que considera importante a posição política de quem pesquisa.

Em relação a primeira questão, consideramos que nossas análises se posicionam a partir do reconhecimento da importância da produção de pesquisadores/as, ativistas, entre outros/as que se autodefinem como travestis, transexuais ou ainda com outras terminologias no campo da transgeneridade. Essa posição defende um deslocamento desses sujeitos para além de colaboradores/as de pesquisas acadêmicas, mas como articuladores/as de intervenções políticas e/ou acadêmicas no Brasil e internacionalmente. Um bom exemplo disso é a articulação da noção de cisheteronormatividade, sendo produzida e desenhada pela militância e/ou intelectualidade trans, em elaborações do transfeminismo, principalmente pela ação de ativistas, acadêmicas ou não, em redes da internet (ANTRA, 2019; MOIRA, 2017).

Isto tem ocorrido na busca para se delimitar, com o prefixo cis, domínios existenciais diferentes daqueles ocupados por travestis, transexuais, entre outros/as que se identificam nos terrenos da transgeneridade (MOIRA, 2017; JESUS, 2014). Deste modo, teríamos uma discursividade cisnormativa como produtora daqueles/as que se identificam com o gênero atribuído no nascimento, independente das identificações como gay ou lésbica. Viviane Vergueiro (2015) alerta à importância de se pensar as categorias de forma interseccionada, algo que Megg Rayara G. de Oliveira (2017) tem produzido desde sua tese de doutorado ao discutir homofobia e racismo. Sem desconsiderar a problemática no uso dos termos cis e trans (MOIRA, 2017), esse último aponta para determinada polissemia dos termos travestilidade e transexualidade e suas apropriações singulares na vida dos sujeitos (LONGARAY; RIBEIRO, 2016).

A segunda questão diz da importância de se identificar quem pesquisa, e como o faz, pois pode indicar uma determinada posição de fala no campo. Propomos aqui a posição de fala para indicar opções teórico-políticas de quem pesquisa e/ou milita com determinados grupos. Essa posição pode se dar na dimensão da alteridade, por reconhecer a legitimidade das demandas daqueles grupos, ou de uma proximidade crítica, por viver questões semelhantes àquelas relacionadas ao seu campo de investigação. Como exemplo, trazemos a construção desse artigo. Nele, temos dois homens gays cisgêneros e uma mulher transexual, todos pertencentes a um projeto de pesquisa mais amplo em que se reconhece os direitos de LGBTQIA+.

Certamente temos outras questões, mas aqui destacamos duas que dizem de uma tensão existente em contexto de pesquisa em que determinadas posições identitárias (intra e extra muros da academia) têm questionado como se dá as relações entre pesquisadores/as e colaboradores/as de pesquisa. A partir de Butler (2015) consideramos que uma pesquisa que não considere o lugar existencial daqueles/as que nos relatam suas histórias, pesquisadores/as que não questionam o sentido de "seu fazer", podem incorrer em atos de violência com determinados sujeitos. Entendemos que a noção de reconhecimento implica nossas pesquisas duplamente, nas análises dos dados que construímos e no modo como nos posicionamos diante dos sujeitos envolvidos.

A noção de reconhecimento não deve ser confundida com a capacidade de se nomear o outro ou a si mesmo, mas sustentar em aberto a questão sobre quem é o outro ou quem sou eu. Essa tensão está de forma 


\section{autêntica}

contundente nas perfomatividades trans, sejam elas identitárias ou não. O problema não é a afirmação de uma identidade travesti ou transexual para nomeação de direitos, mas quando estas são transformadas em universais fechados para outras formas de existências que se constituem a partir e além das normas de gênero. Uma performatividade trans não poderia ser compreendida a partir de uma interioridade do sujeito, mas pela produção de seus atos corpóreos. Nos corpos trans isso poderia ser compreendido próximo a noção de gêneros nômades, proposta por Adriana Sales (2017), "nômades, pois recriam, inventam, trafegam em mundos possíveis e discursos nada ortodoxos, [...] resistem aos estigmas e exclusões" (p. 257).

A noção de regime de verdade em Michel Foucault, segundo Michel Senellart (2018), até 1980 foi guiada pela questão sobre o modo como o discurso se articulava às práticas, a partir daí a questão passou a analisar "por que procedimento, segundo que modo, tendo em vista quais fins um sujeito se liga a uma manifestação da verdade" (p. 316). Diferente do esquema saber-poder, em que o sujeito encontrava objetivado, aqui ele é movido pela ideia de um "governo pela verdade", em que parece se perder "toda exterioridade em relação ao sujeito da enunciação", conforme SENELLART (2018, p. 302). Disto, parece resultar a preferência foucaultiana pela expressão "regime de veridicção". Todavia, Judith Butler (2015) analisa que Foucault daria pouca atenção a figura do outro, no contexto desse regime. Contudo, isto não seria algo decisivo na elaboração foucaultiana, considerando nesse autor que "o próprio ser do si-mesmo é dependente não só da existência do outro em sua singularidade [...], mas também da dimensão social da normatividade que governa a cena do reconhecimento" (BUTLER, p. 36).

Aqui se estabelece um horizonte ético, ainda que imerso nas normas que nos constituem e com as quais lutamos. Butler afirma que diante do outro nossa pergunta deveria ser "como devo tratar-te?" (2015, p. 38). Nisso existe um desejo de oferecer reconhecimento a um "tu". Em Butler a opacidade produzida pelos limites do reconhecimento está nas impossibilidades de respostas perenes, acabadas ou prontas para a pergunto sobre o "si mesmo." Isso nos alerta que a formação docente não deveria se preocupar em fornecer categorizações do sujeito a professores/as, um saber acabado sobre o que é o outro. Todavia, seria importante manter em aberto a possibilidade desse outro se manifestar a partir da verdade que o constitui em determinado momento.

\section{Transfobia e formação docente: relatos de Leona, uma professora de coragem}

Nos últimos anos temos certo número de pesquisas acadêmicas sobre as implicações entre diversidade sexual e gênero na formação docente (OLIVEIRA; OLIVEIRA, 2018; GROSSI; OLIVEIRA; SILVA, 2017; ALTMANN, 2013; FRANÇA; CALSA, 2011), sendo que a investigação sobre transfobia nesse contexto é extremamente reduzida e por vezes tocam indiretamente na questão (FRANCO, 2018; JUNIOR, LOPES, SILVA, 2017; FRANCO; CICILLINI, 2016; TORRES, 2012). Como exemplo, destacamos um pequeno número de trabalhos realizados por pesquisadoras trans, com experiência docente. Elas apresentam em suas pesquisas trechos com relatos autobiográficos em que a transfobia na educação aparece de forma marcante (SALES, 2019; OLIVEIRA, 2017; MOIRA, 2017; REIDEL, 2013; ANDRADE, 2015).Algumasanálises dessas pesquisadoras temos utilizado ao longo do presente artigo, porém não temos condições de aprofundar, de modo desejável, todas elas no presente texto. Nelas temos localizado regimes de veridicção em que um sujeito se reconhece e é reconhecido como trans.

Nesses relatos e análises de pesquisadores trans é impressionante como a coragem dessas autoras desafia a cisnormatização acadêmica ao trazerem suas vidas para o trabalho acadêmico. Todavia, de modo geral, em todas as pesquisas apontadas anteriormente, constatamos que essa discussão da formação docente ainda 


\section{autêntica}

é incipiente e pouco abrangente. Poderíamos supor que a existência de pesquisadoras e professoras trans indicariam uma diminuição da transfobia, porém as pesquisas não apontam para isto. Além desses casos serem bastante pontuais, muitas trans assumiram sua performatividade atual depois de certa segurança profissional e/ou conclusão da graduação (FRANCO; CICILLINI, 2016; TORRES, 2012). Termos uma posição crítica não diz de uma acusação aqueles/as que estão envolvidos/as na área da formação docente, mas da necessidade de aprofundarmos nossos debates acerca das questões trans nos contextos educacionais. Nesse contexto a afirmação de Amara Moira ganha uma grande capacidade analítica.

Faz diferença a travesti dizer-se "homem" ou "mulher" diante das tantas violências a que estará sujeita? Deixará em algum dos casos de ser expulsa de casa, da escola, de ver as portas do mercado formal se fecharem, de encontrar na prostituição mais precária a quase que única possibilidade de subsistência, de ser brutalmente objetificada nas ruas, de ter sua expectativa de vida girando ao redor dos trinta e cinco anos? (MOIRA, 2017, p. 370).

A voz de Amara Moira faz eco a tantas outras perfomatividades, dos domínios trans, que experimentaram uma escola hostil e cruel. Ela nos indica a precariedade da cena do reconhecimento de travestis na escola. Cabe aqui uma pergunta. Como a formação docente pode contribuir para que cena do reconhecimento de pessoas trans na escola não seja tão precária?Para dialogar com essa questão, apresentamos nessa seção alguns relatos de uma entrevista narrativa, ocorrida em 2017, com uma jovem professora trans, moradora de uma cidade de pequeno a médio porte, próxima de Belo Horizonte. Consideramos que a entrevista narrativa possibilita uma posição reflexiva tanto de quem narra como daquele que registra o que é falado, processo que ocorre a partir de uma questão geradora, sem interrupções ou questões além do que foi narrado (MUYLAERT [et al], 2014). Um clima de confiança e abertura foi um requisito para a construção de empatia com nossa narradora (CUNHA, 1997).

Leona relatou que se assumiu publicamente numa perfomatividade feminina já como professora, mas sua transexualidade foi gestada em processos de reconhecimento de si nem sempre fáceis. O questionamento sobre sua identidade de gênero surge ainda na infância, quando ela começa a desejar ser igual à irmã, começa a imitá-la e manifesta preferência por brinquedos tidos "como de meninas." Os relatos de Xxxx vão ao encontro do entendimento de Marina Reidel (2013), de que as meninas trans se percebem no registro do feminino, preferindo brincadeiras ou brinquedos do sexo oposto desde a mais tenra idade. A pergunta e/ou o reconhecimento sobre o modo como o outro deseja ser tratado, também é fundamental diante das crianças.

O reconhecimento de si, num processo de subjetivação trans, se dá quando Leona começa a se aproximar de uma vizinha transexual que morava em frente à sua casa. De uma observação inicial, a relação torna-se uma amizade, que forneceu apoio emocional e social, de orientação (guia de conselhos) e num modelo no qual nossa narradora se espelhava.

Aí eu fui pra casa de uma amiga, ela me recebeu super bem, mas, eu sabia que seria só durante um tempo... que eu tinha que procurar o meu rumo, vamos dizer assim. (...), fiquei sozinha na casa da minha amiga e eu devo muito isso a ela. E, essa amiga, e até então não era amiga, que era a transexual que morava em frente a minha casa, mas que nessa fase da minha vida já era amiga e me orientava, disse "olha, Leona, agora é a hora de você fazer a sua transformação". (Leona, 2017).

Considerando a experiência de Xxxx, a proximidade com uma vizinha trans possibilitou formas de reconhecimento de si que não eram oferecidas na família.Nesse contexto uma verdade trans, dentro de um 


\section{autêntica}

DOI https://doi.org/10.31639/rbpfp.v12i24.339

regime de veridicção, fornece significado aos processos de subjetivação de Xxxx. Esse processo não se inicia nesse encontro com a vizinha, mas neste se organizam de modo importante. Foi a vizinha a principal incentivadora para que Xxxx iniciasse seu processo de transformação corporal e quem cedeu sua casa, ainda que provisoriamente, para que ela se instalasse quando foi expulsa de casa. Desse modo, percebemos a importância de redes de apoio para trans, em que se é possível experimentar formas de reconhecimento além do discurso transfóbico.

Para Silva e Cerqueira-Santos (2014), a rede social de apoio se constitui em um importante fator de proteção durante toda a vida humana, podendo ser composta pela família, colegas de trabalho/escola/universidade, pares e comunidade, proporcionando o apoio necessário para gerenciar situações consideradas adversas e ambientes adequados ao desenvolvimento. No caso de pessoas trans, a rede é mais rara e permeada por questões relacionadas ao preconceito (SILVA; CERQUEIRA-SANTOS, 2014). Isso nos indica a importância de pensar a seguinte questão. Como as redes de apoio trans operariam e/ou poderiam se constituir nas escolas? Como na formação docente se poderia trabalhar sobre a necessidade dessas redes?

Nessa seara, emerge também a importância do círculo de amizades em que nossa narradora experimenta formas de reconhecimento, pois esse círculo forneceu apoio emocional e social. Além disso, foram seus amigos que escolheram para ela o nome Leona, estabelecendo uma relação entre os cabelos loiros e compridos que Leona utilizava na com a personagem interpretada pela atriz Carolina Dieckmann, na novela Cobras e Lagartos exibida no ano de 2006, pela TV Globo. Aqui temos o papel do coletivo na cena do reconhecimento; ser reconhecida como mulher dentro de um determinado grupo de referência a partir de uma verdade que a reconhece como mulher trans.

Todo mundo me pergunta! Porque geralmente tem uma associação com o nome, com o nome de registro e o meu não tem. Mas, eu acostumei e gostei e foi ficando e, hoje em dia, todo mundo fala assim: "se você mudar seu nome vai ser Leona mesmo!?Por que você não põe outro?". E eu não me vejo com outro nome que não seja Luana. O nome é forte, né? Todo mundo fala, pergunta, se eu não penso em outro nome mais comum, e eu falo assim: "não, não tem outro! Tem que ser Luana". É Leona! Não vejo outro nome... Mas, a pessoa tem um estranhamento a primeira vez que vê o nome... "Luana?". Mas não vejo outro nome não. Eu até pensei em outro, mas não consigo achar outro que seja melhor que Luana não. Pra mim, não. (Leona, 2017).

Conforme argumenta Santos (2017), é junto ao nome que se designam as relações de gênero e sexualidade na constituição do elemento que possibilita primeiramente o reconhecimento de um sujeito e designa imediatamente um pertencimento de gênero. O nome social, a questão do uso de banheiros, o direito de escolher as formas de brincar, entre tantas outras questões, dizem da cena do reconhecimento de pessoas trans. A ausência, ou baixa visibilidade, destes debates na formação docente não significa uma neutralidade, mas um posicionamento a partir da cisheteronormatividade que atinge o desenvolvimento e aprendizagem de pessoas trans desde a mais tenra idade.

É importante frisar que a construção corporal de Leona só se iniciou após a finalização de seus estudos e de ter se formado em pedagogia. Seu ingresso na docência foi por seleções e concursos públicos. Ela atribui sua permanência à estabilidade que o cargo público oferece. Contribui para isto a realização de um trabalho exemplar que não deixava margens para contestações e para utilização de subterfúgios para serem utilizados como fundamentos para reprovação em estágios probatórios, tampouco para abertura de processos administrativos disciplinares contra ela. Essa necessidade de estar sempre melhor que os demais para se 
validar na docência é sem dúvida um efeito da transfobia na vida de docentes trans, sendo diversas situações observadas em outras pesquisas com professoras trans (SALES, 2019; SANTOS, 2017; FRANCO; CICILLINI, 2016; ANDRADE, 2015; XXXX, 2012).

Durante todo o período em que foi professora da escola de um município de pequeno porte, em Mina Gerais, no início de sua carreira como docente, Leona sofreu diversas situações de preconceito e discriminação. Inicialmente, a secretaria de educação do município tentou lotá-la numa escola de difícil acesso como forma de impedir que ela assumisse a vaga. Em seguida, a diretora da escola, onde foi designada, lhe submeteu a uma situação degradante, destinando-a a despensa como local para que ela lecionasse.

Nos espaços escolares, a conduta de Leona sempre esteve sob constante vigilância e chegaram, inclusive, a espalhar boatos de que ela possuía preferência por alunos do sexo masculino. O que se observa, portanto, é que a disseminação de boatos, bem como a vigilância constante a que foi submetida, estão associados ao discurso transfóbico que liga diretamente a experiência trans à prostituição e à hipersexualização dos corpos trans, reduzindo-os meramente às fantasias e práticas sexuais. Ainda que a experiência da prostituição possa ter significados importantes nos domínios das travestilidades (SALES, 2019; MOIRA, 2017), operar uma redução da travesti ou da mulher trans a sua sexualidade também é um efeito do discurso transfóbico.

Leona, no início de sua carreira profissional, para tentar diminuir a vigilância sobre sua conduta, optou por utilizar roupas mais discretas para trabalhar, ocultado ainda com um bustiê apertado, os seios que haviam começado a crescer.

\footnotetext{
Mas, na escola foi difícil, a transformação, depois porque eu não sabia como me comportar. Aí, a princípio, eu trabalhava com roupas mais discretas, vamos dizer assim... procurando esconder os seios...eu usava um bustiê mais apertado... E, os funcionários comentavam e tudo, mas era bem tranquilo. Entre os funcionários [era tranquilo], mas entre a comunidade, eu não tinha coragem de assumir aquela posição [identidade transexual] de uma vez só. Eu usava o bustiê para tampar os seios... e as roupas eram mais fechadas... bem discretas... Aí, com isso, eu fui conquistando meu espaço, quando eu fui ver eu já estava indo [trabalhar] com uma calça mais apertada, e agora já chegou até no decote, vamos dizer assim [risos]. Já não tem mais nenhum problema com isso. Mas, foi uma transformação que se deu aos poucos. (Leona, 2017).
}

Embora a rede de apoio social de Leona não tenha sido suficiente para que ela se posicionasse diante dessas ocorrências discriminatórias no ambiente escolar, este cenário foi se modificando. Foi importante nesse processo uma reaproximação com a mãe que se tornou mais presente, bem como o aumento do reconhecimento de colegas de trabalho e estudantes. Leona foi se transformando não só na aparência, mas foi se tornando cada vez mais professora, mais resistente e confiante e, com o passar do tempo, foi se posicionando melhor diante das situações de transfobia. Sua performatividade de gênero e profissional se produzia à medida que experimentava processos de reconhecimento no seu cotidiano. 


\section{autêntica}

DOI https://doi.org/10.31639/rbpfp.v12i24.339

\section{Considerações finais}

O discurso transfóbico e suas relações com a formação docente pode ser analisado de diversos ângulos, pois ainda é uma questão pouco explorada.Ainda que existam iniciativas que enfrentem tal discursivos, elas não podem ser consideradas suficientes. Consideramos que essa situação produz dificuldades para o reconhecimento de pessoas trans e dos saberes por elas produzidos nos terrenos da escola. Isto prejudica uma análise crítica das cisheteronormatividade na educação de modo amplo. Desde modo, consideramos que tal situação produz uma precarização humana na cena do reconhecimento de pessoas trans na ambiência educacional.Isso se deve, sobretudo, ao fato de que os profissionais da área da educação se constituem pelas lógicas da cisheteronormativividade. O discurso transfóbico que exclui da inteligibilidade performatividades de gênero como àquelas de $X x x x$, nem mesmo são percebidos por muitas das pessoas que transitam pelo cotidiano escolar. Certamente isto se relaciona com as lógicas da formação docente, pela raridade ou ausência dessa temática nesse contexto.

Apontamos três considerações sobre como trabalhar a importância do reconhecimento das pessoas trans na formação docente. Primeiro, entender que lutamos com nosso próprio quadro normativo, em que não raro essas pessoas são des/classificadas de diversos modos: para determinadas ocupações, por transtornos médico-psiquiátricos, por inadequação de seus corpos, entre outras questões. A pergunta de Amara Moira denuncia justamente essas formas de des/classificação. "Faz diferença a travesti dizer-se "homem" ou "mulher" diante das tantas violências a que estará sujeita? (2017, p. 370).

A segunda consideração é sustentar a tensão da pergunta sobre "como você quer ser tratado", bem como compreender a legítima instabilidade dos relatos oferecidos como respostas. Certamente, isto diz das vidas de todos nós, quando pensamos nas próprias alterações de compreensão do "si-mesmo" que produzimos durante a vida. Quando narramos nossas histórias fazemos em nosso presente, sempre constrangido por uma normatividade e orientado por nossos afetos atuais, por isso, mudamos fatos, reconstruímos cenas, damos cores diferentes ao nosso pretérito. Leona se reconhece e é reconhecida a partir de um quadro de referências possíveis sobre o que é ser trans, num dado regime de veridicção das performatividades de gênero.

Por fim, a terceira consideração traz uma certa dramaticidade necessária à cena do reconhecimento de pessoas trans. Precisamos compreender nosso fracasso em reconhecer de modo mais reflexivo o que é uma travesti, uma/um transexual, uma pessoa não binária, entre outras expressões de gênero a partir da cisgeneridade.Isto não pela nossa incapacidade intelectual, ou coisa semelhante, mas pelo regime de veridicação que nos constitui. Compreendemos o mundo por uma gramática marcada pela cisnormatização, como o uso do termo trans. Este, se constitui numa precariedade que buscamos manter para dialogarmos com um determinado grupo de pessoas, porém é preciso reconhecer o quanto ele é insuficiente e sempre vizinho do risco de generalizações. Aqui precisamos nos aproximar das verdades trans, entender sua gramática e produzir condições para uma cena de reconhecimento trans na educação. Isto exige uma aproximação daquilo que eles/as têm produzido como conhecimento, seja este acadêmico, da militância, das artes, enfim, das formas em que a manifestação dessa verdade trans emerge como potência existencial e politicamente posicionada. Assim, entender e/ou se aproximar das redes de apoio trans ganha grande importância.

Por fim, consideramos ser um exercício ainda muito exigente trazer esse debate à formação docente. Isto tem pioradona atualidade em que a intimidação, a perseguição e a violência contra gênero e sexualidade têm sido explicitadas até mesmo na gestão pública de nosso país. Todavia, aquilo que de modo incipiente definimos como a produção de uma verdade trans tem sido um ato de coragem dessas pessoas que não desistem de serem fiéis ao que "são" e a potência do que podem se tornar. Como todos/as os/as demais, as pessoas trans se constituem, em interdependências sociais, a partir de seus paradoxos, ou seja, na singularidade de nossas existências em que o outro se torna imprescindível. 


\section{autêntica}

DOI https://doi.org/10.31639/rbpfp.v12i24.339

\section{Referências}

ALTMANN, H. Diversidade sexual e educação: desafios para a formação docente. Sexualidad, Salud y Sociedad - Revista Latinoamericana [en linea]. 2013, (13), 69-82. Disponível em: <https://www.redalyc.org/ articulo.oa?id=293325757003> Acesso em: 15 agosto, 2019.

ANDRADE, L. N. de. Travestis na escola: assujeitamento e resistência à ordem normativa. 1. ed. Rio de Janeiro: Metanoia, 2015.

ANTRA. Associação Nacional de Travestis e Transexuais. ANTRA realiza seu $23^{\circ}$ encontro nacional de travestis e transexuais em Tapes/RS ,2019. Disponível em:

<https://antrabrasil.org/2019/11/21/antra-realiza-seu-23o-encontro-nacional-de-travestis-e-transexuais-em-tapes-rs/>Acesso em: 01 março, 2020.

BUTLER, J. Relatar a si mesmo: crítica da violência ética. Tradução de Rogério Bettoni. Belo Horizonte: Autêntica, 2015.

BUTLER, J. Problemas de Gênero: feminismo e subversão da identidade. Trad. de Renato Aguiar. Rio de Janeiro: Civilização Brasileira, 2003.

CUNHA, M. I. da. Conta-me agora!: As narrativas como alternativas pedagógicas na pesquisa e no ensino. Revista da Faculdade de Educação, São Paulo, v. 23, n. 1/2, p. 185-195, jan./dez. 1997. Disponível em: <http:// www.revistas.usp.br/rfe/article/view/59596/62695> Acesso em: 14 abril, 2019.

FRANÇA, F. F.; CALSA, G. C. Gênero e Sexualidade na Formação Docente: desafios e possibilidades. Santa Maria, v. 24, n. 02, jul/dez 2011, p. 111-120. Disponível em: <https://periodicos.ufsm.br/sociaisehumanas/ article/view/2828/2858> Acesso em: 11 março, 2019.

GROSSI, M. G. R.; OLIVEIRA, E. S.; SILVA, L. de C. Transexualidade na formação do professor da educação básica: desvelando a realidade brasileira. Rev. Humanidades, Fortaleza, v. 32, n. 2, p. 180-192, jul./dez. 2017. Disponível em: <https://periodicos.unifor.br/rh/article/view/7475/5546> Acesso em: 08 abril, 2019.

FOUCAULT, M. Do governo dos vivos: Curso no Collège de France (1979-1980). Tradução de Eduardo Brandão. São Paulo: WMFMartins Fontes, 2018.

FRANCO, N. Transfobia e cotidiano escolar: impactos na relação docente/discente. Revista de Educação Pública. R. Educ. Públ. Cuiabá, v. 27, n. 65/1, p. 469-486, maio/ago. 2018. Disponível em: <http://periodicoscientificos.ufmt.br/ojs/index.php/educacaopublica/article/view/6592/43> Acesso em: 22 junho, 2019.

FRANCO, N.; CICILLINI, G. A. Travestis, transexuais e transgêneros na escola: um estado da arte. Cadernos de Pesquisa, São Paulo, v. 23, n.2, p. 122-137, maio/ago. 2016. Disponível em:<http://www.periodicoseletronicos.ufma.br/index.php/cadernosdepesquisa/article/view/5349/3272> Acesso em: 16 setembro, 2019.

JESUS, J. G. Interlocuções teóricas do pensamento transfeminista. In: Jesus, Jaqueline Gomes. (Org.). Transfeminismo: Teorias e práticas. Rio de Janeiro: Metanoia, 2014. 


\section{autêntica}

DOI https://doi.org/10.31639/rbpfp.v12i24.339

LONGARAY, D.; RIBEIRO, P. R. C. Travestis e transexuais: corpos (trans)formados e produção da feminilidade. Rev. Estud. Fem., Florianópolis, v. 24, n. 3, p. 761-784, Dec. 2016. Disponível em:<http://www.scielo. br/pdf/ref/v24n3/1806-9584-ref240300761.pdf>Acesso em: 27 junho, 2019.

MOIRA, A. O cis pelo trans. In: Revista Estudos Feministas, Florianópolis, v.25, n.1, pp. 365- 373, Abr. 2017. Disponível em: <http://www.scielo.br/scielo.php?script=sci_arttext\&pid=S0104026X2017000100365\&lng=e n\&nrm=iso > Acesso em: 21 maio, 2018.

MUYLAERT, C. J. [et al]. Entrevistas narrativas: um importante recurso em pesquisa qualitativa. Rev. esc. enferm. USP, São Paulo, v. 48, n. spe2, p. 184-189, Dec. 2014. Disponível em:<http://www.scielo.br/scielo. php?script=sci_arttext\&pid=S0080-62342014000800184\&lng=en\&nrm=iso> Acesso em: 22 março, 2019.

OLIVEIRA, A. L. A. R. M. de; OLIVEIRA, G. G. S. de. Novas tentativas de controle moral da educação: conflitos sobre gênero e sexualidade no currículo e na formação docente. Educação Unisinos 22(1):1625, janeiro-março 2018. Disponível em:<http://revistas.unisinos.br/index.php/educacao/article/viewFile/ edu.2018.221.02/60746116> Acesso em: 26 maio, 2019.

OLIVEIRA, M. R. G. de. O diabo em forma de gente: (r)existências de gays afeminados, viados e bichas pretas na educação. Editora Prismas: Curitiba. 2017.

REIDEL, M. A pedagogia do salto alto: histórias de professoras transexuais e travestis na educação brasileira. 2013. 147f. Dissertação (Mestrado em Educação) - Programa de Pós-Graduação em Educação, Universidade Federal do Rio Grande do Sul, Porto Alegre, 2013.

SALES, A. Travestis Brasileiras e escolas (da vida): cartografias do movimento social organizado aos gêneros nômades. CRB. Curitiba, 2019.

SANTOS, D. B. C. dos. Docências Trans*: entre a decência e a abjeção. 2017. 447f. Tese (Doutorado) Universidade Federal do Paraná - Curitiba, 2017.

SENELLART, M. Situação do curso. In: FOUCAULT, M. Do governo dos vivos: Curso no Collège de France (1979-1980). Tradução de Eduardo Brandão. São Paulo: WMFMartins Fontes, 2018, p. 295-323.

SILVA, B. de B.; CERQUEIRA-SANTOS, E. Apoio e suporte social na identidade social de travestis, transexuais e transgêneros. Rev. SPAGESP, Ribeirão Preto, v. 15, n. 2, p. 27-44, dez. 2014. Disponível em:<http:// pepsic.bvsalud.org/scielo.php?script=sci_arttext\&pid=S167729702014000200004\&lng=pt\&nrm=iso $>$ Acesso em: 14 março, 2020.

VERGUEIRO, V. Por inflexões decoloniais de corpos e identidades de gênero inconformes: uma análise autoetnográfica da cisgeneridade como normatividade. 2015. 244f. Dissertação (mestrado) - Universidade Federal da Bahia - Salvador, 2015.

TORRES, M. A. A emergência de professoras travestis e transexuais na escola: heteronormatividade e direitos nas figuraçóes sociais contemporâneas. 2012. 362F. Tese (Doutorado em Psicologia). Programa de Pós-graduação em Psicologia, Universidade Federal de Minas Gerais, Belo Horizonte, 2012. 
